\title{
Design of a fractional order PID controller for electro hydraulic actuator
}

Erinna Dyah Atsari ${ }^{* 1}$, Abdul Halim ${ }^{* 2}$

Universitas Indonesia, Indonesia ${ }^{1,2}$

\section{Article Info}

\section{Keywords:}

Electro Hydraulic Actuator, PID Controller,

Fractional Calculus, Fractional Orde PID,

Ziegler Nichols

\section{Article history:}

Received: November 15, 2020

Accepted: January 1, 2021

Published: February 28, 2021

\section{Cite:}

Dyah Atsari, E., \& Halim, A. (2021). Design of a Fractional Order PID Controller for Electric Hydraulic Actuator. Kinetik: Game

Technology, Information System, Computer

Network, Computing, Electronics, and

Control, 6(1).

https://doi.org/10.22219/kinetik.v6i1.1151

*Corresponding author.

Erinna Dyah Atsari, Abdul Halim

E-mail address:

erinna.dyah@ui.ac.id

a.halim@ui.ac.id

\begin{abstract}
Electro hydraulic actuators are more used especially in industries that demand high levels of accuracy. A common problem with this type of actuator is consistency in fluid flow control. PID controllers can accelerate the achievement of defined output values, eliminate offsets, and reduce maximum overshoots but result in considerable errors. Therefore, it is necessary to design controllers that can reduce errors significantly. In this research, a Fractional Order PID controller is developed to reduce maximum overshoots and steady state. Unlike conventional PID controllers that have three $\mathrm{K}_{\mathrm{p}}, \mathrm{K}_{\mathrm{i}}, \mathrm{K}_{\mathrm{d}}$ parameters, in the Fractional Order PID controller, there are extra two parameters of the $\lambda$ and $\mu$. The $K_{p}, K_{i}, K_{d}$ parameters were selected using the Ziegler Nichols method with a 1st order approach with a delay time. Meanwhile, the $\lambda$ and $\mu$ parameters were selected the best value to make the system response better. The results of the design of the Fractional Order PID controller were evaluated using matlab simulation. The simulation results showed that the Fractional Order PID controller was able to reduce the steady state error response by $0.5 \%$, and the maximum overshoots by $17.4 \%$. From this result, it can be noted that the Fractional Order PID controller is better than conventional PID.
\end{abstract}

\section{Introduction}

Electro hydraulic actuators have been widely used in a variety of applications such as position control, valve actuation, robotic arm joint drives and damper systems. These applications can be found in industrial machines, robots and transportation equipment. These actuators consist of a cylindrical arrangement controlled by servo valve and are designed to generate static forces of up to $7000 \mathrm{~N}$ with dynamic forces of up to $\pm 1500 \mathrm{~N}$ [1][2]. This type of actuator is used especially for machines that require a high level of accuracy and consistency to produce maximum quality products [3]. The problem often arising in Electro Hydraulic Actuators (EHA) is the consistency of fluid motion in the hydraulic system. Fluid motion is greatly influential in the hydraulic work process in which the fluid flow must be under control to work properly. In addition to fluid regulation, non-linear hydraulic movements may also affect their work and function. These non-linear characteristics arise as a result of fluid flow, leakage, saturation, friction, and external disturbances [4].

To deal with the problems arising in electro hydraulic actuators, this tool was designed by utilizing the latest material and structure technology. Moreover, improvement in actuator performance was also carried out by applying appropriate control methods such as PID controller. This type of controller is applied by adjusting (tuning) three parameters, namely $K_{p}, K_{i}$, and $K_{d}$. However, the conventional PID controller still leaves problems, especially regarding the output error in steady state [5]. Conventional PID controller can accelerate the system output to reach the set point, eliminate offsets, produce large initial changes and reduce maximum overshoots, but in use, it still results in sizable errors. Electro hydraulic actuators are very important tools for industrial processes, but electro hydraulic actuators have problem because must provides linear movement, fast response, and accurate position with heavy loads. To address these problems, it is necessary to design a PID controller that has a higher degree of control, known as the Fractional Order PID (FOPID) controller denoted by $\mathrm{PI}^{\lambda} \mathrm{D}^{\mu}[6]$. The design of the feedback control system using Fractional Order PID controllers has been adopted in this study because it is simple and robust when applied within specified operating range. In contrast to conventional PID controller, Fractional Order PID controller utilizes fraction calculus. Fractional Order PID controller has five parameters, namely $\mathrm{K}_{\mathrm{p}}, \mathrm{K}_{\mathrm{i}}, \mathrm{K}_{\mathrm{d}}, \lambda$, and $\mu$. Greater number of parameters presents challenges to selecting parameter values [7].

In the last decade, the development of PID controller has led to that of Fractional Order PID controller. From several research results, the performance of Fractional Order PID controller revealed better results compared to those of conventional PID such as hybrid systems and hydro turbine systems [8]. From several research results, there are methods for selecting the parameters for Fractional Order PID controller. Ziegler Nichols method in designing Fractional

Cite: Dyah Atsari, E., \& Halim, A. (2021). Design of a Fractional Order PID Controller for Electric Hydraulic Actuator. Kinetik: Game Technology, Information System, Computer Network, Computing, Electronics, and Control, 6(1). https://doi.org/10.22219/kinetik.v6i1.1151 
Order PID controller was used by several researchers like in the case of servo motor controller [9][10]. In this research, the application of fractional order PID controller was carried out on electro hydraulic actuator system. PID controller parameters were selected using the Ziegler Nichols method and manual for fractional order. The non-linear characteristics of this system were approximated by a linear model at a certain value. The linear actuator model could not be directly designed by the controller because of its high order [4]. Order reduction using the order system $1^{\text {st }}$ approach with a time delay was executed first. Fractional order PID controller was designed for this lower order model. The design results were tested in a simulation.

\section{Research Method}

\subsection{Electro Hydraulic Actuator Model}

The electro hydraulic actuator system is a piston drive system in which the power is obtained from compressing the fluid flow. Flow pressure is regulated through a valve controlled by the servo system. The working principle of the electro hydraulic actuator system is shown in Figure 1 [11][12].

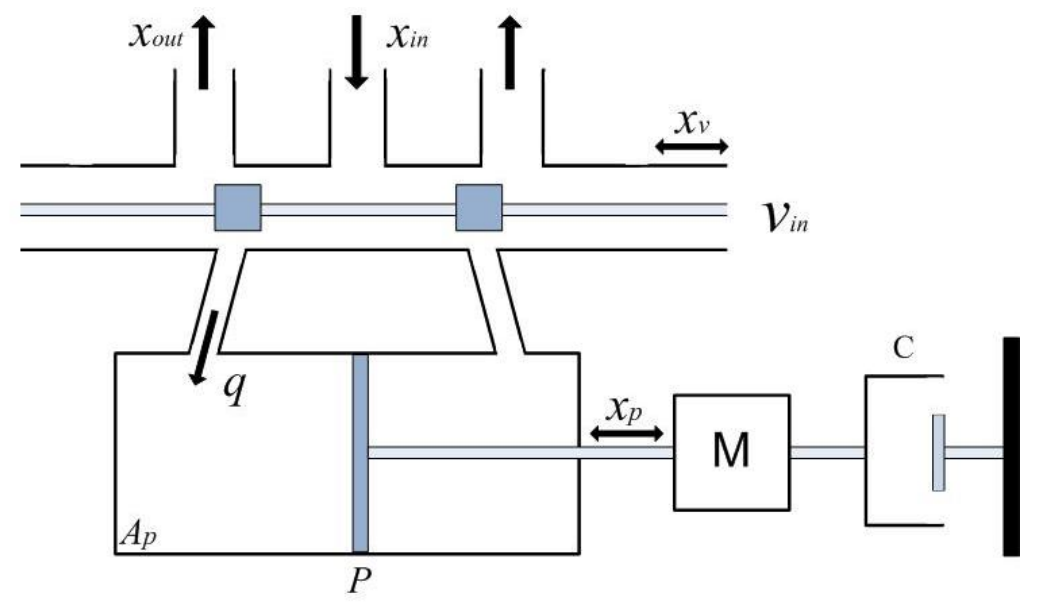

Figure 1. Electro Hydraulic Actuator Model

In Figure 1, there is a pipe in which the fluid flow will enter $\left(x_{i n}\right)$ and exit $\left(x_{\text {out }}\right)$ as a result of the voltage of valve servo $v_{i n}$ and the displacement of valve $x_{v}$. Parameter $A p, M, C$ being the piston surface area, load mass, and viscocity immersion coefficient. Meanwhile, $x_{p}$ refers to the displacement of piston position and $P$ refers to the piston hydraulic pressure. In an electro hydraulic actuator system, the change in the fluid flow rate input around the nominal value is directly proportional to the change in hydraulic pressure [13]. In this research, fluid flow must moving the valve servo which can pressure displacement to be stable so that it can be applied in tests such as machine structure testing. When the fluid flow is not controlled, it will result in pressure which will damage the testing of the machine structure [14]. The input signal is the voltage on the servo valve while as the output is the static force. It can be seen in the figure that the system consists of three mathematical models, namely the hydraulic actuator model $G_{\text {akt }}$, valve servo model $G_{\text {sk }}$ and static force model $G_{P}$. The transfer function of each part is as Figure 2, Equation 1, Equation 2, and Equation 3 [15].

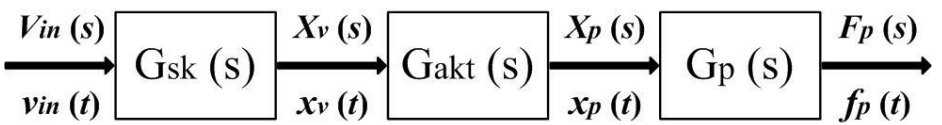

Figure 2. Block Diagram of the Electro Hydraulic Actuator Subsystem

$$
\begin{gathered}
\mathrm{G}_{\mathrm{sk}}=\frac{\mathrm{Kv}}{\left(\frac{\mathrm{s}}{\omega_{\mathrm{nv}}}\right)^{2}+\left(\frac{2 \zeta}{\omega_{\mathrm{nv}}}\right) \mathrm{s}+1} \\
\mathrm{G}_{\mathrm{akt}}=\frac{\left[\frac{\mathrm{K}_{\mathrm{Q}}}{\mathrm{A}_{\mathrm{P}}}\right]}{\left[\frac{\mathrm{s}^{2}}{\omega_{\mathrm{h}}^{2}}+\frac{2 \delta_{\mathrm{h}}}{\omega_{\mathrm{h}}}+1\right]\left[s+\frac{\mathrm{K}_{\mathrm{ct}} \mathrm{K}_{\mathrm{L}}}{\mathrm{A}_{\mathrm{P}}^{2}}\right]} \\
\mathrm{G}_{\mathrm{p}}=\mathrm{Ms}^{2}+\mathrm{Cs}+\mathrm{K}_{\mathrm{L}}
\end{gathered}
$$

(c) 2021 The Authors. Published by Universitas Muhammadiyah Malang

This is an open access article under the CC BY SA license. (https://creativecommons.org/licenses/by-sa/4.0/) 
Kinetik: Game Technology, Information System, Computer Network, Computing, Electronics, and Control

From the previous three equations, the controller for the EHA system model was designed as Equation 4.

$$
G_{c}=\frac{\left[\frac{K_{Q} K_{v}}{A_{P}}\right]\left[M s^{2}+C s+K_{L}\right]}{\left[\frac{s^{2}}{\omega_{h}^{2}}+\frac{2 \delta_{h}}{\omega_{h}} s+1\right][s+P]\left[\left(\frac{s}{\omega_{n v}}\right)^{2}+\left(\frac{2 \zeta}{\omega_{n v}}\right) s+1\right]}
$$

The equation of Hydro-Mechanical frequency as Equation 5.

$$
\omega_{\mathrm{h}}=\sqrt{\frac{4 \beta_{\mathrm{e}} \mathrm{A}_{\mathrm{P}}^{2}}{\mathrm{MV_{ \textrm {t } }}}}
$$

The damping ratio of electro hydraulic actuator as Equation 6.

$$
\delta_{h}=\frac{K_{c t}}{A_{P}} \sqrt{\frac{\beta_{e} M}{V_{t}}}+\frac{C}{4 A_{P}} \sqrt{\frac{V_{t}}{\beta_{e} M}}
$$

\subsection{PID and Fractional Order PID Controller}

\subsubsection{PID Controller}

Conventional PID controller consists of three paramaters, namely $K_{p}, K_{i}$, and $K_{d}$. PID Controller is shown in the following Equation 7 and Figure 3 [13].

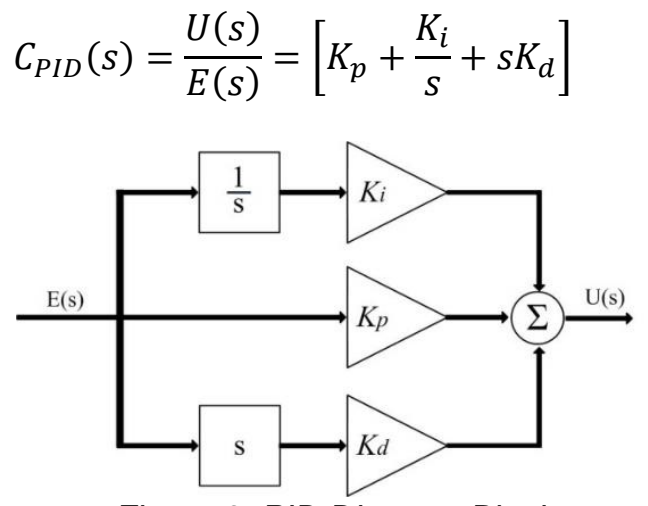

Figure 3. PID Diagram Block

There are many methods of selecting parameters, one of which is that of Ziegler Nichlos for the $1^{\text {th }}$ order system with time delay. The selection of PID parameters can be carried out, referring to Table 1 and Equation 8 [16][17].

$$
G(s)=\frac{\mathrm{Ke}^{-\mathrm{sL}}}{\mathrm{Ts}+1}
$$

Table 1. Ziegler Nichols Parameter Model

\begin{tabular}{cccc}
\hline PID Type & $K_{p}$ & $T_{i}$ & $T_{d}$ \\
\hline P & $\frac{T}{L}$ & $\infty$ & 0 \\
PI & $0,9 \frac{T}{L}$ & $\frac{L}{0,3}$ & 0 \\
PID & $1,2 \frac{T}{L}$ & $2 L$ & $0,5 L$ \\
\hline
\end{tabular}

The reaction curve method is based on the results of the reaction curve in an open loop system. The system with open loop is given a step function signal. The S-shaped curve has two constants, $L$ and $T$, which increase after an interval of $L$. In the results of the reaction curve, a line is drawn that will touch the curve line. This tangent is used to cut the abscissa and the maximum line. PID controller can be used on multiple machine and easy to apply in a machine.

Cite: Dyah Atsari, E., \& Halim, A. (2021). Design of a Fractional Order PID Controller for Electric Hydraulic Actuator. Kinetik: Game Technology, Information System, Computer Network, Computing, Electronics, and Control, 6(1). https://doi.org/10.22219/kinetik.v6i1.1151 
However, PID using ZN method still has disadvantages and errors so it is necessary to be given parameters in integral gain and derivative gain [18].

\subsubsection{Fractional Order PID Controller}

Fractional Order PID controller is the development of Integral and Derivative Controller with integer order into that of fractional. It is possible with a mathematical support of fractional calculus. This type of PID is denoted by $\mathrm{PI}^{\lambda} \mathrm{D}^{\mu}$ $n$ which $\lambda$ and $\mu$ is a fraction that has a value range of 0 to 1 . Furthermore, the $\mathrm{PI}^{\lambda} \mathrm{D}^{\mu}$ notation means that the PID Integral component is of $\lambda$ order while the Derivative one is of $\mu$ order. With these two extra parameters, the Fractional Order PID controller has a greater number of parameters than that of conventional, that is $K_{p}, K_{i}, K_{d}$, $\lambda$, and $\mu$ [7]. Mathematically, the differential-integral operator is denoted as ${ }_{a}^{t} D^{\alpha}$, in which Equation 9 [8].

$$
{ }_{a}^{t} D^{\alpha} \begin{cases}\frac{d^{\alpha}}{d t^{\alpha}} & , \text { Re } \alpha>0 \\ 1 & , \text { Re } \alpha=0 \\ \int_{a}^{t}(d \tau)^{-\alpha} & , \text { Re } \alpha<0\end{cases}
$$

with $\alpha \in \mathbb{C}$ being fractional order and $a, t$ being operational border. There are several definitions of fractional order integral differential, one of which is that of Caputo as Equation 10 [5][10].

$$
{ }_{a}^{t} D^{\alpha} f(t)=\frac{1}{\Gamma(m-\alpha)} \int_{0}^{t} \frac{f^{(m)}(\tau)}{(t-\tau)^{\alpha-m+1}} \quad, m-1<\alpha<m
$$

with $\Gamma(m-\alpha)$ : Gamma function, $m$ and $\alpha$ real number. Laplace Transformation from the Equation 10 to Equation 11.

$$
\mathcal{L}\left\{{ }_{0} D_{t}^{\alpha} f(t)\right\}=s^{\alpha} F(s)
$$

with the transfer function of Fractional Order PID controller as Equation 12 [2][10].

$$
C_{F O P I D}(s)=\frac{U(s)}{E(s)}=\left[K_{p}+\frac{K_{i}}{s^{\lambda}}+s^{\mu} K_{d}\right]
$$

The structure of Fractional Order PID is shown in the following Figure 4.

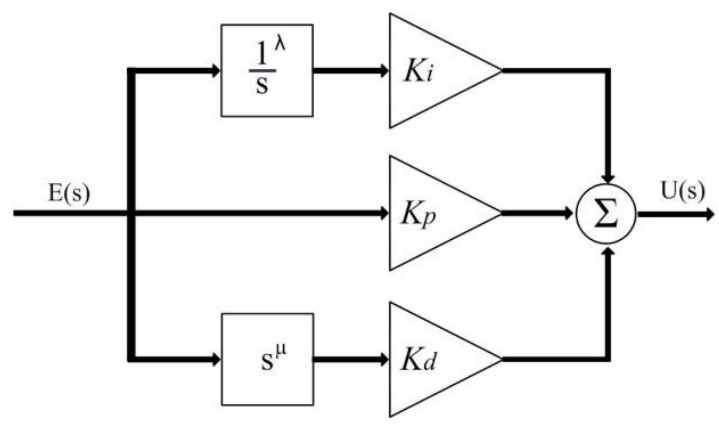

Figure 4. Diagram Block of the Fractional Order PID

The characteristics of parameter $\lambda$ and $\mu$ in the Fractional Order PID controller are shown in Figure 5 [8]. Parameter $\lambda$ and $\mu$ were selected in the range between $0<\lambda<1$ and $0<\mu<1$. Fractional Order PID controller showed minimum error in steady state errors, eliminating steady state errors and robustness to high frequency disturbance as well as variations in output gain. It also reduces the sensitivity to parameter changes so that it can compare with conventional controllers [19][20]. The design of the feedback control system using Fractional Order PID controllers has been adopted in this study because it is simple and robust when applied within specified operating range. In contrast to conventional PID controller, Fractional Order PID controller utilizes fraction calculus. Fractional Order PID

(C) 2021 The Authors. Published by Universitas Muhammadiyah Malang

This is an open access article under the CC BY SA license. (https://creativecommons.org/licenses/by-sa/4.0/) 

controller has five parameters, namely $\mathrm{K}_{\mathrm{p}}, \mathrm{K}_{\mathrm{i}}, \mathrm{K}_{\mathrm{d}}, \lambda$, and $\mu$. Greater number of parameters presents challenges to selecting parameter values.

The characteristics of parameter $\lambda$ and $\mu$ in the Fractional Order PID (FOPID) controller are shown in the following Figure 5 [8][16].

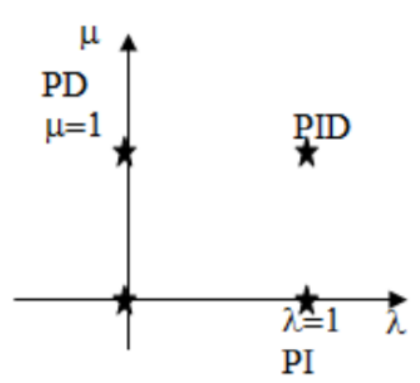

Figure 5. Characteristics of Fractional Order PID Controller

Based on the characteristics, parameter $\lambda$ and $\mu$ in the Fractional Order PID controller were implemented to the controller with the value between $0<\lambda<1$ and $0<\mu<1$. Fractional Order PID controller presents minimum error in steady state errors, and robustness to high frequency disturbance as well as variations in output gain. It also reduces the sensitivity to parameter changes so that it can compare with conventional controllers.

\section{The Discussion of Design and Results}

The design of conventional PID controller and that of the closed loop fractional order PID is presented in the diagram block in Figure 6 . $R(s)$ refers to the input voltage and $Y(s)$ refers to the output load force. The actuator system fluid flow is controlled by $\mathrm{C}(\mathrm{s})$ in the form of a conventional PID controller or that of Fractional Order PID (FOPID). The transfer function of the electro hydraulic actuator model in the controller design is shown in Equation 4. However, since the order of the equation was $5^{\text {th }}$ order while the control design used the Ziegler Nichlos method for the $1^{\text {st }}$ order system with a time delay, the actuator model order was reduced to $1^{\text {st }}$ order [20].

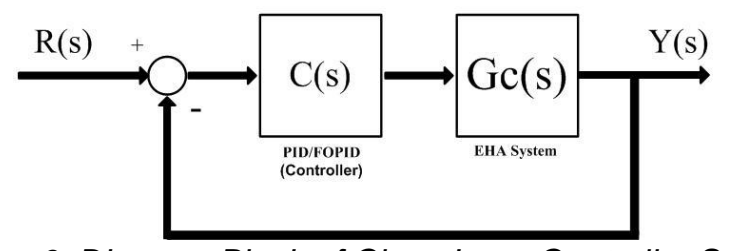

Figure 6. Diagram Block of Close Loop Controller System

To design conventional PID controller and that of FOPID, the electro hydraulic actuator system employed parameter values, referring to Table 2 [1].

Table 2. The Value of EHA Parameter

\begin{tabular}{ccc}
\hline Symbol & Definition & Value \\
$\mathrm{M}$ & Load mass & $0,893 \mathrm{~kg}$ \\
$V_{t}$ & Piston chamber volume & $2,364 \times 10^{-6} \mathrm{~m}^{3}$ \\
$\mathrm{Ap}$ & Piston area & $2,364 \times 10^{-4} \mathrm{~m}^{2}$ \\
$\mathrm{C}$ & Coefficient of viscous & $10 \mathrm{Ns} / \mathrm{m}$ \\
$\omega_{\mathrm{nv}}$ & Natural frequency & $1500 \frac{\mathrm{rad}}{\mathrm{s}}$ \\
$\mathrm{Z}$ & Damping ratio & 0,7 \\
$\beta_{e}$ & Effectiveness of modulus & $1,75 \times 10^{9} \frac{\mathrm{N}}{\mathrm{m}^{2}}$ \\
$K_{Q}$ & Flow coefficient & $3,33 \times 10^{-3} \frac{\mathrm{m}^{2}}{\mathrm{~S}}$ \\
$K_{L}$ & Coefficient static actuator & $4,83 \times 10^{8} \frac{\mathrm{N}}{\mathrm{m}}$ \\
$K_{c t}$ & Coefficient of flow pressure & $1,6585 \times 10^{-11}$ \\
\hline
\end{tabular}

Cite: Dyah Atsari, E., \& Halim, A. (2021). Design of a Fractional Order PID Controller for Electric Hydraulic Actuator. Kinetik: Game Technology, Information System, Computer Network, Computing, Electronics, and Control, 6(1). https://doi.org/10.22219/kinetik.v6i1.1151 
The previous parameters are substituted with Equation 4, thus obtaining the following electro hydraulic actuator system model as Equation 13.

$$
G c(s)=\frac{5,245 \times 10^{15} s^{2}+5,873 \times 10^{16} s+2,837 \times 10^{24}}{s^{5}+1,946 \times 10^{5} s^{4}+7,633 \times 10^{9} s^{3}+4,217 \times 10^{13} s^{2}+7,204 \times 10^{16} s+5,976 \times 10^{19}}
$$

As seen in Equation 8, the system order is $5^{\text {th }}$ order, which means that it has a high order thus making it possible to undergo difficulties in designing the reference model design. To be able to use Ziegler Nichols method with order model one and a time delay, the model order was reduced with First Order Plus Deadtime (FOPDT) model and the following model as Equation 14.

$$
G c_{r e d(s)}=\frac{4.74 \times 10^{4}}{8.4272 \times 10^{-4} s+1} e^{-3.9206 \times 10^{-4} s}
$$

The transfer function of the reduction model is determined by the criteria of design parameters, among others, the settling time specified in the reference model as much as $\leq 20$ seconds, the percentage of maximum overshoots as much as $\leq 50 \%$ out of the response output [3].

\subsection{PID Controller}

Designing the controller design in the electro hydraulic actuator system with closed loop Fractional Order PID and PID controller with the right controller strategy, may increase bandwidth, overcome problems in oscillations, become resistant to disturbances and reduce the maximum overshoots. In the present research, the $5^{\text {th }}$ order system was approached with the $1^{\text {st }}$ order system. In making this approach, a step response curve was created as Figure 7.

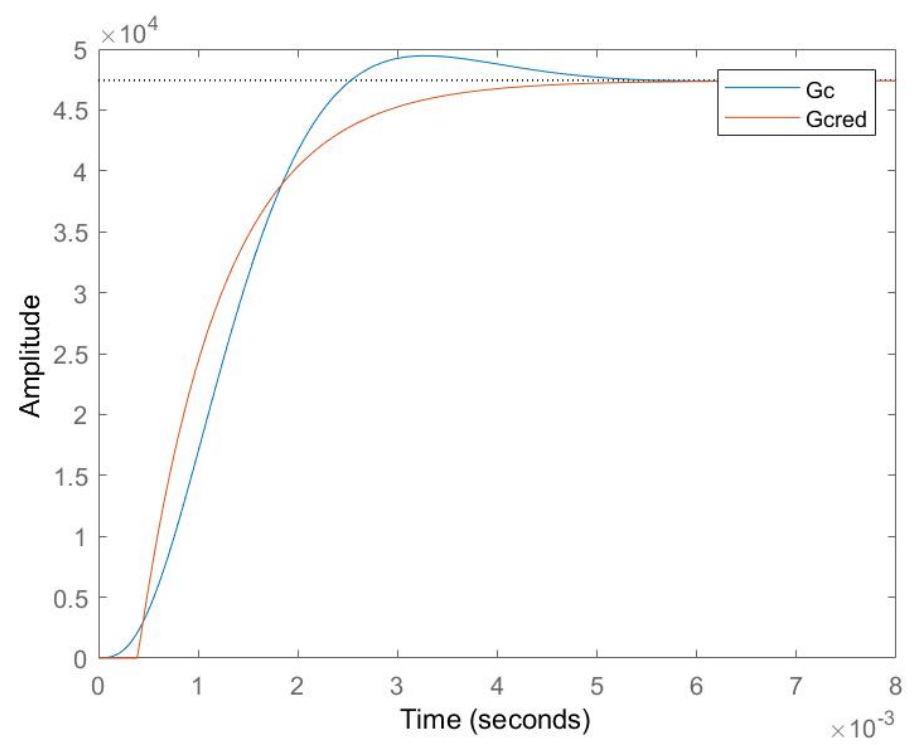

Figure 7. Electro Hydraulic Actuator Step Response Approach

The approach of $1^{\text {st }}$ order with time delay from the step response of the $5^{\text {th }}$ order system refers to Equation 4 . Therefore, the constant amplifier value $(\mathrm{Kc})$ is obtained through the root locus or the gain margin value of the system plot bode above. This research employed the Ziegler Nichols first tuning method, obtaining the value $T$ as much as $3,3092 \times 10^{-8}$ and $L$ as much as $4,3827 \times 10^{-4}$. Based on the algorithm, the values for the PID controller parameters using Ziegler Nichols tuning method are obtained as follows: $K_{p}=9.06 \times 10^{-5}, K_{i}=0.11$, and $K_{d}=1.98 \times 10^{-8}$. Hence, the following transfer function of PID controller as Equation 15.

$$
\mathrm{C}_{\mathrm{PID}}(\mathrm{s})=\left(9,06 \times 10^{-5}\right)+\frac{0,11}{\mathrm{~s}}+\mathrm{s}\left(1,98 \times 10^{-8}\right)
$$

Based on the closed loop diagram block of Ziegler Nichols PID controller in Figure 6, the following as Equation 16.

(c) 2021 The Authors. Published by Universitas Muhammadiyah Malang

This is an open access article under the CC BY SA license. (https://creativecommons.org/licenses/by-sa/4.0/) 


$$
\frac{\mathrm{Y}(\mathrm{s})}{\mathrm{R}(\mathrm{s})}=\frac{\mathrm{C}_{\mathrm{PID}}(\mathrm{s}) \cdot \mathrm{Gc}(\mathrm{s})}{1+\mathrm{C}_{\mathrm{PID}}(\mathrm{s}) \cdot \mathrm{Gc}(\mathrm{s})}
$$

The following is a close loop transfer function with PID controller as Equation 17.

$$
G_{P I D}(s)=\frac{P_{1} s^{4}+P_{2} s^{3}+P_{3} s^{2}+P_{4} s+P_{5}}{s^{6}+P_{6} s^{5}+P_{7} s^{4}+P_{8} s^{3}+P_{9} s^{2}+P_{10} s+P_{11}}
$$

In which, $P_{1}$ has a value of $1,0434 \times 10^{8}, P_{2}$ of $4,7625 \times 10^{11}, P_{3}$ of $5,6989 \times 10^{16}, P_{4}$ of $2,5699 \times 10^{20}, P_{5}$ of $2,9318 \times 10^{23}, P_{6}$ of $1,9454 \times 10^{5}, P_{7}$ of $7,7351 \times 10^{9}, P_{8}$ of $4,2639 \times 10^{13}, P_{9}$ of $1,2901 \times 10^{17}, P_{10}$ of $3,1674 \times 10^{20}$, and $P_{11}$ of $2,9318 \times 10^{23}$. According to the results of the step response parameters of the conventional PID controller electro hydraulic actuator system with the Ziegler Nichols $1^{\text {st }}$ order method, the value of settling time is 0,008 seconds, rise time is $4.2722 \times 10^{-4}$ seconds and maximum overshoots is $52,4039 \%$.

\subsection{Fractional Order PID Controller}

In the Fractional Order PID controller, there Fractional Order are two extra $\lambda$ and $\mu$. Each parameter $\lambda$ and $\mu$ uses integral and derivative gains. In this reseach, several values of $\lambda$ and $\mu$ were combined to obtain a better system response. The values of $\lambda$ and $\mu$ were obtained in the range of $0<\lambda<1$ and $0<\mu<1$. Simulation was conducted by combining the values of $\lambda$ and $\mu$, therefore, obtaining the step response as presented in Table 3 and Figure 8 . Meanwhile, the values of $K_{p} . K_{i}, K_{d}$ used refer to the results achieved in the conventional PID parameters.

Table 3. The Result of FOPID Controller Response

\begin{tabular}{cccc}
\hline$\lambda$ value & $\mu$ value & Maximum Overshoots $(\%)$ & Settling Time (seconds) \\
\hline 1 & 0,9 & 87 & 0,024 \\
0,9 & 1 & 100,53 & 0,00016 \\
0,9 & 0,9 & 30 & 0,005 \\
1 & 1,9 & 119 & 0,0098 \\
1,9 & 1 & 13 & Oscillation \\
1,9 & 1,9 & Oscillation & Oscillation \\
\hline
\end{tabular}


Figure 8. The Graphic of Parameter FOPID Variation Response

Thus, the combination of the best $\lambda$ and $\mu$ values is obtained, that is the value of $\lambda=0,9$ and $\mu=0,9$. The following is the FOPID controller transfer function as Equation 18.

$$
\mathrm{C}_{\mathrm{FOPID}}(\mathrm{s})=\left(9,06 \times 10^{-5}\right)+\frac{0,11}{\mathrm{~s}^{0.9}}+\mathrm{s}^{0.9}\left(1,98 \times 10^{-8}\right)
$$



Equation 19.

$$
G_{F O P I D}(s)=\frac{Q_{1} s^{3,8}+Q_{2} s^{2,9}+Q_{3} s^{2,8}+Q_{4} s^{2}+Q_{5} s^{1,9}+Q_{6} s^{1,8}+Q_{7} s+Q_{8} s^{0,9}+Q_{9}}{s^{5,9}+Q_{10}+Q_{11}+Q_{12}+Q_{13}+Q_{14}+Q_{15}+Q_{16}+Q_{17}+Q_{18}+Q_{19}+Q_{20}}
$$

In which, $Q_{1}$ has a value of $1,0434 \times 10^{8}, Q_{2}$ of $4,7509 \times 10^{11}, Q_{3}$ of $1,1686 \times 10^{9}, Q_{4}$ of $5,4201 \times 10^{14}, Q_{5}$ of $5,3208 \times 10^{12}, Q_{6}$ of $5,6442 \times 10^{16}, Q_{7}$ of $6,0702 \times 10^{15}, Q_{8}$ of $2,5699 \times 10^{20}, Q_{9}$ of $2,9318 \times 10^{23}, Q_{10}$ of $\left(1,9454 \times 10^{5}\right) s^{4,9}, \quad Q_{11}$ of $\left(7,6308 \times 10^{9}\right) s^{3,9}, \quad Q_{12}$ of $\left(1,0434 \times 10^{8}\right) s^{3,8}, Q_{13}$ of $\left(4,2638 \times 10^{13}\right) s^{2,9}, Q_{14}$ of $\left(1,1686 \times 10^{9}\right) s^{2,8}, \quad Q_{15}$ of $\left(5,4201 \times 10^{14}\right) s^{2}, Q_{16}$ of $\left(7,2029 \times 10^{16}\right) s^{1,9}, \quad Q_{17}$ of $\left(5,6442 \times 10^{16}\right) s^{1,8}, Q_{18}$ of $\left(6,0702 \times 10^{15}\right) s, Q_{19}$ of $\left(3,1674 \times 10^{20}\right) s^{0,9}, Q_{20}$ of $2,9318 \times 10^{23}$. Where, used $f$ ot $f$ for creates a new fractional order transfer function object. The important thing in an object " $s$ " is to look for acceptable and realized estimates to differential operators, $s^{\lambda}$, and $s^{\mu}$. The special case of the FOPID controller when $\lambda$ and $\mu$, can make system results change because the integral and diferential orders are variational, FOPID controller has better adaptability and fexibility and bigger potential to obtain better control performance. According to the results of step response parameters of FOPID controller electro hydraulic actuator system, the value of settling time is 0,005 seconds, and maximum overshoots is $30 \%$.

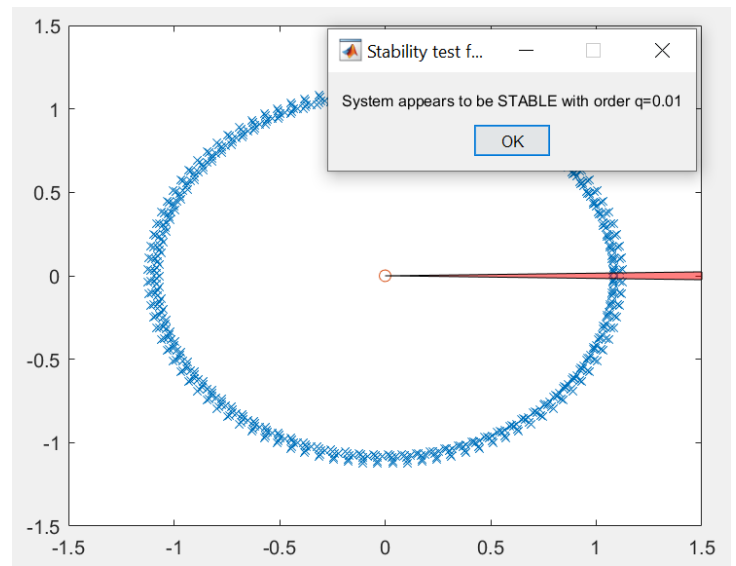

Figure 9. Stability of the FOPID Controller EHA System

The stability parameters in the Fractional Order PID controller are $\mathrm{K}=1 ; \mathrm{q}=0,01$; err $=2,8156 \times 10^{-22}$. The following Figure 10 represents the result of comparison between the PID controller electro hydraulic actuator system transfer function and that of Fractional Order PID controller (FOPID).
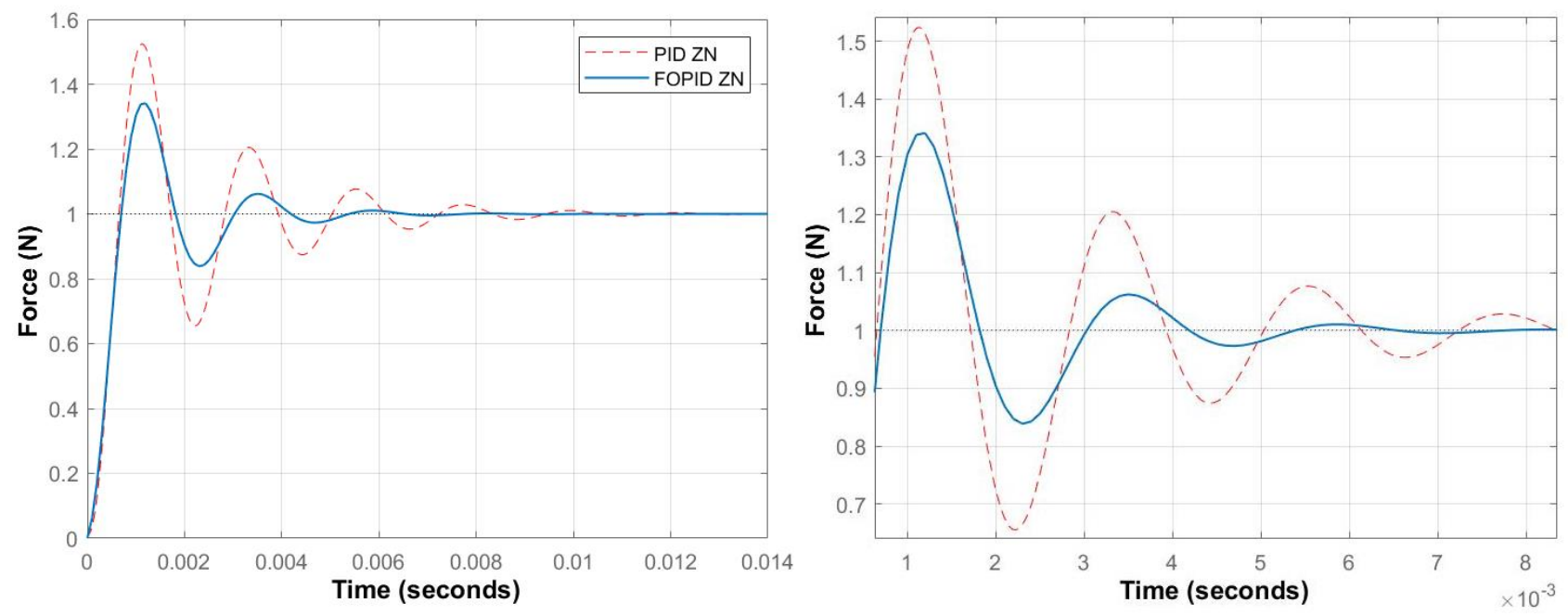

Figure 10. Comparison of Step Response between PID and FOPID Controller System

(c) 2021 The Authors. Published by Universitas Muhammadiyah Malang

This is an open access article under the CC BY SA license. (https://creativecommons.org/licenses/by-sa/4.0/) 
Based on the simulation results, it can be noted that the electro hydraulic actuator system that was not provided with a controller results in an unstable system response. On the other, when given PID conventional controller or that of Fractional Order PID, it results in electro hydraulic actuator system response be stable as Figure 9. In PID conventional controller, the results of rise time is $4.2722 \times 10^{-4}$ seconds, settling time is 0.008 seconds, overshoots is $52.4039 \%$, and the value of ITAE is $4,059 \times 10^{-6}$. In Fractional Order PID controller, the results of rise time is $4.9372 \times 10^{-4}$ seconds, settling time is 0.005 seconds, overshoots is $30,1131 \%$, and the value of ITAE is $2,284 \times 10^{-8}$.

This proves that the electro hydraulic actuator system utilized as a plant has a value that matches the characteristics of the electro hydraulic actuator system. The fractional order PID controller response system has a faster specified time than that of the PID controller and has a lower maximum overshoot. The steady state response characteristics of the $1^{\text {st }}$ order system is measured based on the steady state error $\left(\mathrm{e}_{\mathrm{ss}}\right)$; in the system without controller, it shows steady state error at the level of $2.1068 \times 10^{5} \%$. In contrast, in the system with conventional PID controller and fractional order PID controller present steady state error at the level of $0.5 \%$, while the value of maximum overshoot is at the level of $17,4 \%$.

\section{Conclusion}

The electro hydraulic actuator system with PID controllers and PID has three parameters, namely $K_{p}, K_{i}, K_{d}$; as for Fractional Order PID Controller, there are two extra fractional order $\lambda$ and $\mu$. Parameter $\lambda$ and $\mu$ were selected to make the system response better. The results of simulation show that the Fractional Order PID controller has better maximum overshoots that those of conventional PID, as can be seen by a lower value of maximum overshoots. The results of simulation present that Fractional Order PID controller was able to reduce steady state error response as much as $0,5 \%$, maximum overshoots as much as $17,4 \%$ and Fractional Order PID has a smaller ITAE value when compared to PID, which is $2.284 \times 10^{-8}$. From the results, it can be noted that Fractional Order PID controller presented better results than those of conventional.

\section{Notation}

$\mathrm{K}_{\mathrm{p}}, \mathrm{K}_{\mathrm{v}}, \mathrm{K}_{\mathrm{Q}}$

$\mathrm{V}_{\text {in }}$

: Piston valve, servo valve, flow valve coefficient. : voltage (v).

$\mathrm{X}_{\mathrm{p}}$

: Piston valve displacement $(\mathrm{m})$.

$\omega_{\mathrm{h}}$

: EHA Frequency (Rad/s).

$\delta_{\mathrm{h}}$

: EHA damping ratio

\section{References}

[1] G. N. Sahu, S. Singh, A. Singh, M. Law, "Static and Dynamic Characterization and Control of a High-Performance Electro-Hydraulic Actuator," MDPI Journal Actuators, 2020. https://doi.org/10.3390/act9020046

[2] D. Q. Truong, K. K. Ahn, "Force Control for Press Machines Using an Online Smart Tuning Fuzzy PID Based on a Robust Extended Kalman Filter" Elsevier Expert System with Applications, 2011. https://doi.org/10.1016/j.eswa.2010.11.035

[3] M. M. Jayanegara, Zulfaman, N. A. Mardiyah, "Pemodelan dan Pengaturan Adaptif untuk Sistem Hidrolik Tak-Linier." KINETIK, 1(3), 107-122, 2016. https://doi.org/10.22219/kinetik.v1i3.42

[4] H. Sobfshan, J. Zongxia, W. Chengwen, S. Yaoxing, "Fuzzy Robust Nonlinear Control Approach for Electro-Hydraulic Flight Motion Simulator," Chinese. Journal of Aeronautics, 28, 294-304, 2015. https://doi.org/10.1016/j.cja.2014.12.025

[5] P. Shah, S. Agashe, "Review of Fractional PID Controller" Elsevier Mechatronics 38, 2016. https://doi.org/10.1016/j.mechatronics.2016.06.005

[6] H. S. Li, Y. Luo, Y. Q. Chen, "A Fractional Order Proportional and Derivative (FOPD) Motion Controller: Tuning Rule and Experiments," IEEE Transactions on Control Systems Technology, 18(2):516-20, 2020. https://doi.org/10.1109/TCST.2009.2019120

[7] B. Isabela, F. Silviu, P. Ovidiu, D. Eva, "An Experimental Tuning Approach of Fractional Order Controllers in the Frequency Domain," MDPI Applied Sciences, 2020. https://doi.org/10.3390/app10072379

[8] L. Junyi, C. Qijuan, "Fractional Order Controller Designing with Firefly Algorithm and Parameter Optimization for Hydroturbine Governing System," Mathematical Problems in Engineering, 2015. https://doi.org/10.1155/2015/825608

[9] R.S Barbosa, J.T Machado, I.S Jesus. "Effect of Fractional Orders in the Velocity Control of a Servo System," Compututers and Mathematics with Applications 59 (5):1679-86, 2010. https://doi.org/10.1016/j.camwa.2009.08.009

[10] M. Rinki, B. Manisha, "Design of Optimal PID (FOPID) Controller for Linear System," IEEE International Conference on Micro Electronics and Telecommunication Engineering, 978-1-5090-3411-6, 2016. https://doi.org/10.1109/ICMETE.2016.45

[11] M. G. Skarpetis, F. N. Koumboulis, "Robust PID Controller for Electro - Hydaulic Actuators," IEEE 978-1-4799-0864-6, 2013. https://doi.org/10.1109/ETFA.2013.6648165

[12] A. S. Ahmed, "Sampled Data Observer Based Inter-sample Output Predictor for Electro - Hydraulic Actuators" Elsevier ISA Transactioons, 2015. https://doi.org/10.1016/j.isatra.2015.05.002

[13] C. B. Kadu, C. Y. Patil, "Design and Implementation of Stable PID Controller for Interacting Level Control System" Elsevier $7^{\text {th }}$ International Conference on Communication, Computing and Virtualization, 2016. https://doi.org/10.1016/j.procs.2016.03.097

[14] L. Xiang, C. Z Zhen, C. R. Guang, "Force Loading Tracking Control of on Electro Actuator Based on a Nonlinear Adaptive Fuzzy Backstepping Control Scheme" MDPI Journal Symmetry, 2018. https://doi.org/10.3390/sym10050155

[15] P. Gianluca, S. Salvatore, T. Mario, "Sliding-mode Observers for State and Disturbance Estimation in Electro - Hydraulic Systems" Elsevier Control Engineering Practice, 2018. https://doi.org/10.1016/j.conengprac.2018.02.007

[16] D. Shah, S. Chatterjee, K. Bharati, "Tuning of fractional-order PID controller" Frontiers in Computer, Communication and Electrical Engineering, 2016. https://doi.org/10.1201/b20012-64

Cite: Dyah Atsari, E., \& Halim, A. (2021). Design of a Fractional Order PID Controller for Electric Hydraulic Actuator. Kinetik: Game Technology, Information System, Computer Network, Computing, Electronics, and Control, 6(1). https://doi.org/10.22219/kinetik.v6i1.1151 
[17] D. K. Robin, I. M. Cristina, M. I. Clara, "A novel Auto-tuning Method for Fractional order PI/PD Controllers" Elsevier ISA Transactions, 2016. https://doi.org/10.1016/j.isatra.2016.01.021

[18] A. D. Ali, M. V. Blas, C. Yangquan, S.H. Hossein, "Linear Fractional Order Controllers; A Survey in the Frequency Domain" Elsevier Annual Reviews in Control, 2019. https://doi.org/10.1016/j.arcontrol.2019.03.008

[19] A. D. Mohammad, A. N. Mohammad, "Analysing Stability of Time Delayed Synchronous Generator and Designing Optimal Stabilizer Fractional Order PID Controller using Partical Swarm Optimization Technique," IEEE $2^{\text {nd }}$ International Conference on Power Electronics, Intelligent Control and Energy Systems, 2018. https://doi.org/10.1109/ICPEICES.2018.8897429

[20] S. Ijaz, L. Yan, N. Shahzad, "An Fractional Order Control of Dissimilar Redundant Actuating System Used in Large Air Craft" IEEE, 2017. https://doi.org/10.1109/CCDC.2017.7979145 